\title{
Synthesis of SiOC Base Fibers from Silicone Resin with Low Carbon Content and Control of Surface Functionality by Metal Chloride Treatment in Vapor
}

\author{
Masaki. Narisawa, a , Yayoi. Satoh ${ }^{1, b}$, Ryuichi Sumimoto ${ }^{1, c}$, \\ Takashi Kamegawa ${ }^{2, \mathrm{~d}}$ and Hiromi Yamashita ${ }^{2, \mathrm{e}}$ \\ ${ }^{1}$ Graduate School of Engineering. Osaka Prefecture University, 1-1, Gakuen-Cho, \\ Sakai, 599-8531, Japan \\ ${ }^{2}$ Graduate School of Engineering, Osaka University, 2-1, Yamadaoka, Suita, 565-0871, Japan

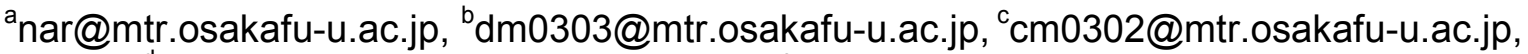 \\ dkamegawa@mat.eng.osaka-u.ac.jp, ’yamashita@mat.eng.osaka-u.ac.jp
}

Keywords: Ceramic fiber, Silicone Resin, Silicon Oxycarbide, Metal Chloride, Heat Stability, $\mathrm{TiO}_{2}$, Crystallization

\begin{abstract}
Melt spinnable silicone resin with a low carbon content was spun to fiber form with an averaged diameter of $16.8 \mu \mathrm{m}$. When the resin fiber was cured by $\mathrm{SiCl}_{4}$ vapor and pyrolyzed at $1273 \mathrm{~K}$ in inert atmosphere, Si-O-C fiber with smooth surface was obtained. The measured tensile strength was relatively low. The fiber, however, showed oxidation resistance during high temperature exposure under an air flow. When the fiber was cured by $\mathrm{TiCl}_{4}$ with an increased vapor pressure at $313 \mathrm{~K}, 40 \%$ mass gain was observed after the curing. $\mathrm{SiO}_{2}-\mathrm{TiO}_{2}$ fiber was obtained by pyrolysis in an air flow, while $\mathrm{SiOC}-\mathrm{TiO}_{2}$ fiber was obtained by pyrolysis in an inert atmosphere. Structure of $\mathrm{TiO}_{2}$ and the resulting fiber surface morphology strongly depended on the temperature and the atmosphere during the pyrolysis.
\end{abstract}

\section{Introduction}

Silicon oxycarbide (Si-O-C) materials derived from silicone resins are known to possess unique properties. Such resins were used as binding agents for $\mathrm{SiC}$ and carbon black filler grains to produce $\mathrm{SiC}$ base dense or porous ceramics by molding, shaping and sintering [1]. On the other hand, abnormally high creep resistance of the simple $\mathrm{Si}-\mathrm{O}-\mathrm{C}$ amorphous was reported and analyzed in detail recently [2,3]. In the starting silicone resin precursors, we paid attention to a kind of the polymethylsilsesquioxane - like resin with low carbon content. It showed high ceramic yield, 83 mass $\%$ at $1273 \mathrm{~K}$, and possessed melt spinnablity in the temperature range of $393-453 \mathrm{~K}$ [4]. The spun fiber, however, did not accept thermal oxidation curing because of its low softening point. The curing by metal chloride vapor was effective to hold the fiber shape during the pyrolysis $[4,5]$. In this article, the properties and structure of the ceramic fibers derived from the melt-spun resin fiber will be described from the viewpoint of curing and pyrolysis conditions. The intrinsic cost of the resin fiber is low, because the starting monomer, $\mathrm{CH}_{3} \mathrm{SiCl}_{3}$, is a major sub product in a silicone industry based on the chemical reaction between metal silicon and $\mathrm{CH}_{3} \mathrm{Cl}$. In addition, polymerization of $\mathrm{CH}_{3} \mathrm{SiCl}_{3}$ does not require special reagents, like sodium or magnesium [6]. Therefore, the resulting fibers are promising as a new class of "conventional" fibers, like glass fibers and carbon fibers.

\section{Experimental}

The polymethylsilsesquioxane - like resin (YR 3370, Momentive Performance Materials Japan) with an analyzed chemical composition of $\mathrm{SiO}_{1.78} \mathrm{C}_{1.22} \mathrm{H}_{3.67}$ was melt-spun to fiber form at $423 \mathrm{~K}$ with using an Ar gas pressure. Detailed condition of the melt spinning was described in a previous article [4]. The averaged diameter of the spun fiber is $16.8 \mu \mathrm{m}$. The curing process of the spun fiber was 
performed by placing fiber bundles in a covered vat $\left(800 \mathrm{~cm}^{3}\right)$ with $10 \mathrm{ml}$ of $\mathrm{SiCl}_{4}$ or $\mathrm{TiCl}_{4}$ in a Teflon dish for $1 \mathrm{~h}$. The curing procedure was performed in a glove bag with flowing nitrogen. During the $\mathrm{SiCl}_{4}$ curing, the temperature of the system was kept at room temperature, while the $\mathrm{TiCl}_{4}$ curing required higher temperature, $313 \mathrm{~K}$. The $\mathrm{SiCl}_{4}$ cured fiber was pyrolyzed at $1273 \mathrm{~K}$ in an Ar gas flow. The obtained Si-O-C fiber was exposed to an air flow at high temperatures to estimate the oxidation resistance. The $\mathrm{TiCl}_{4}$ cured fiber was placed in ambient for 1 day to hydrolyze the incorporated $\mathrm{TiCl}_{4}$ by humidity. The fiber was successively pyrolyzed in an air flow up to 873,1073 or $1273 \mathrm{~K}$ to obtain $\mathrm{SiO}_{2}-\mathrm{TiO}_{2}$ fibers. On the other hand, $\mathrm{SiOC}-\mathrm{TiO}_{2}$ fiber was obtained by pyrolysis of the same cured fiber at $1273 \mathrm{~K}$ in an Ar gas flow.

\section{Result and Discussion}

Si-O-C fiber derived from the silicone resin cured by $\mathrm{SiCl}_{4}$ vapor. After the $\mathrm{SiCl}_{4}$ curing, mass gain of the fiber was 2-3 mass $\%$. The ceramic yield after pyrolysis at $1273 \mathrm{~K}$ was 87 mass $\%$, and the averaged tensile strength was $0.32 \mathrm{GPa}$. After the exposure of the $\mathrm{Si}-\mathrm{O}-\mathrm{C}$ fiber for $3 \mathrm{~h}$ at 1511 or $1606 \mathrm{~K}$ in an air flow, mass losses of -1.7 or -2.7 mass $\%$ was observed respectively. As the oxidation temperature increases, a line of cristobalite, $21.7^{\circ}$, became apparent. The sharp line, however, always existed with broad amorphous silica-like line even at 1606K [7]. On the other hand, reference pure silica fiber (Grade N, silica content beyond 99.9\%) was completely crystallized beyond $1511 \mathrm{~K}$. Figure 1 shows SEM images of heat-treated Si-O-C fibers and the reference pure silica fibers after $3 \mathrm{~h}$ heat treatment at $1606 \mathrm{~K}$. The pure silica fiber is completely fused together. Bending creep of individual fiber is apparent. The Si-O-C fiber also shows surface cracks. Curling and fusing of the individual fiber are not apparent as compared with those in the pure silica fiber. Only the partial fusing is observed. It corresponds to the limited oxidation at the Si-O-C fiber surface. The crystal growth and fusing of the fiber are suggested to proceed in the formed silica layer on the surface, which protects inner core of the $\mathrm{Si}-\mathrm{O}-\mathrm{C}$ fibers.
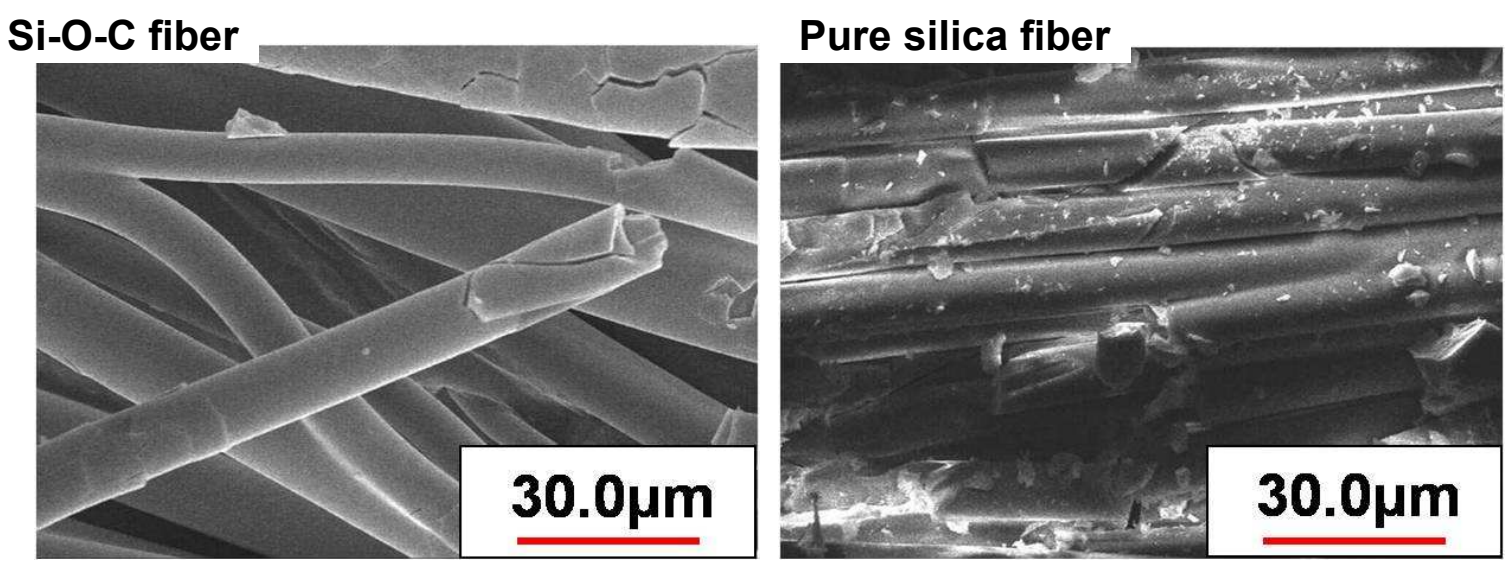

Fig.1 SEM images of the fibers after the heat treatment in air flow at $1611 \mathrm{~K}$ for $3 \mathrm{~h}$.

$\mathrm{SiO}_{2}-\mathrm{TiO}_{2}$ and $\mathrm{SiOC}-\mathrm{TiO}_{2}$ fibers derived from the silicone resin cured by $\mathrm{TiCl}_{4}$ vapor. After the exposure of the resin fibers to $\mathrm{TiCl}_{4}$ vapor for $8 \mathrm{~h}$ and successive hydrolysis, $40 \%$ mass gain was observed. This value was far larger than the mass gain after the $\mathrm{SiCl}_{4}$ curing. Perhaps, $\mathrm{TiCl}_{4}$ not only cross-linked the resin but also penetrated into the resin network to achieve a state of swelled gel. After the pyrolysis, ceramic fibers containing a large amount of $\mathrm{TiO}_{2}$ were obtained. Figure 2 shows photo images of the $\mathrm{TiCl}_{4}$ cured resin fibers, the fibers after pyrolysis in an air flow and the fibers after pyrolysis in an Ar flow. The cured fibers were somewhat curled as compared with the as-spun straight fibers. The fibers pyrolyzed in an air flow hold transparent appearance, while the fibers pyrolyzed in an Ar flow become black. 


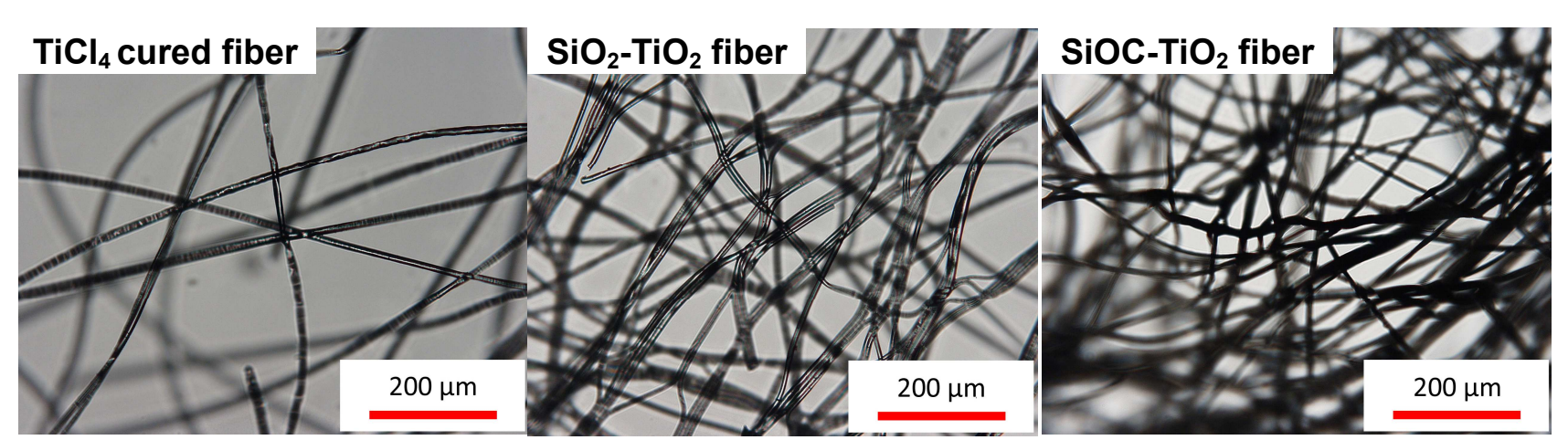

Fig.2 Photo images of the $\mathrm{TiCl}_{4}$ cured and $1273 \mathrm{~K}$ pyrolyzed fibers by transmitted light.

Figure 3 shows the XRD patterns of the pyrolyzed fibers. In the cases of the pyrolysis in an air flow, the fibers are almost amorphous up to $873 \mathrm{~K}$. At $1073 \mathrm{~K}$, broad lines assigned to anatase become apparent. At $1273 \mathrm{~K}$, weak lines assigned to rutile are observed with the dominant anatase phase. In the case of the pyrolysis in an Ar flow at $1273 \mathrm{~K}$, however, the dominant phase is rutile. The formed phase of $\mathrm{TiO}_{2}$ apparently depends on the pyrolysis conditions. Perhaps, the resin matrix surrounding amorphous $\mathrm{TiO}_{2}$ domains restricted crystal growth, and the efficiency of such restriction depended on the resin densification caused by the pyrolysis.

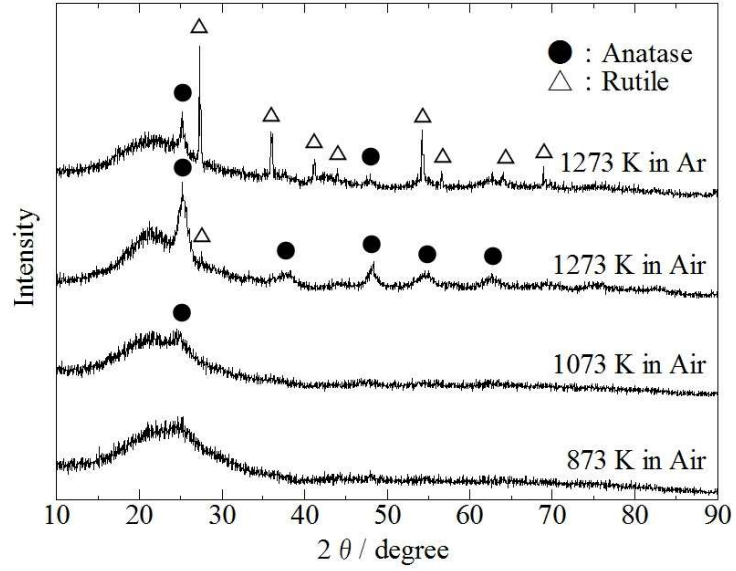

Fig. 3 XRD patterns of the $\mathrm{TiCl}_{4}$ cured fiber surface after pyrolysis with various conditions.

Figure 4 shows the SEM images of the pyrolyzed fibers. At $873 \mathrm{~K}$ in an air, surface of the fiber is smooth. At $1073 \mathrm{~K}$, small grains in the size of 50-100 nm are observed on the fiber surface. At $1273 \mathrm{~K}$, relatively large grains in the size of $1-2 \mu \mathrm{m}$ exits with the dominant small grains. The number of the large grain is, however, small. At the same pyrolysis temperature under an Ar gas flow, the fiber surface is mainly covered by large grains.
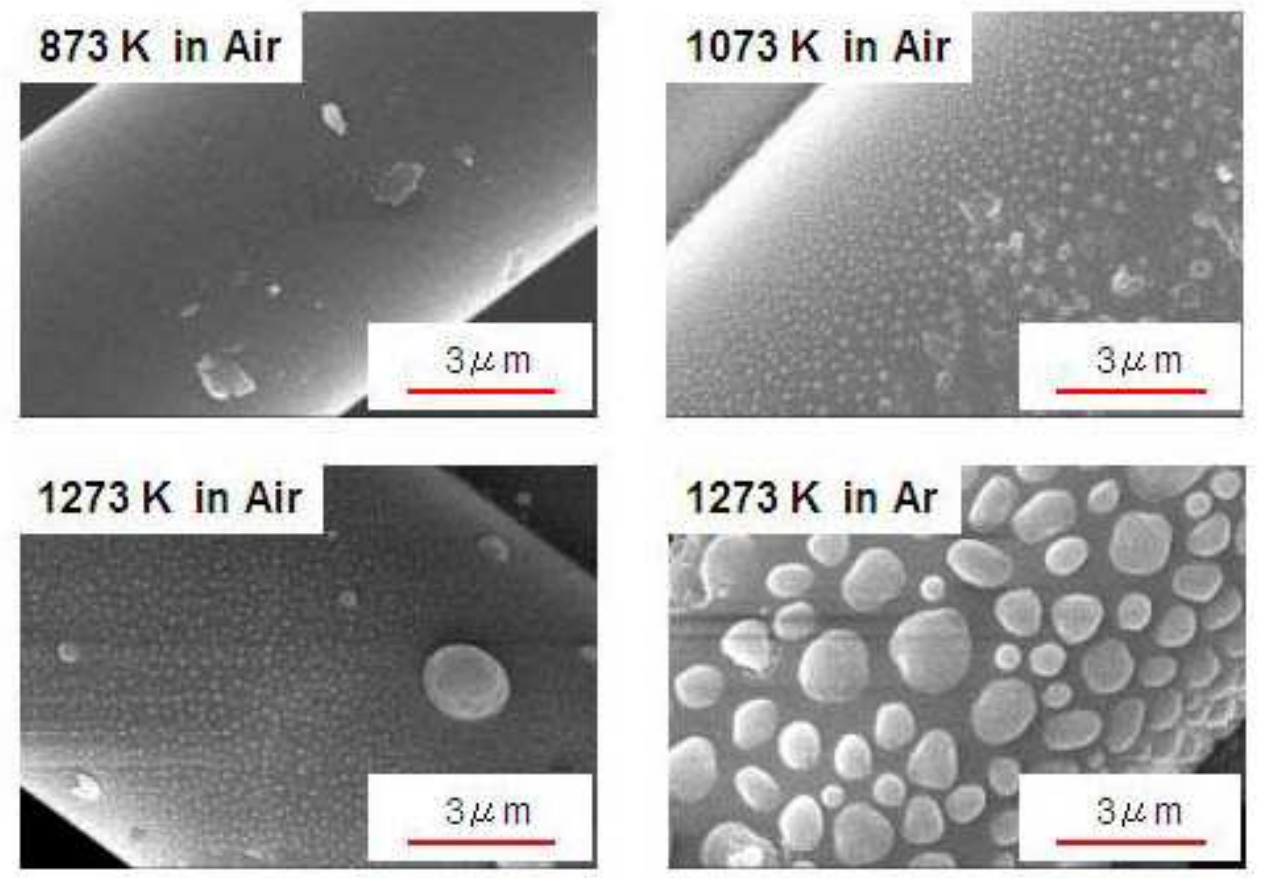

Fig.4 SEM images of the $\mathrm{TiCl}_{4}$ cured fiber surface after pyrolysis with various conditions. 
From the consistency among the SEM images and the XRD patterns, it is supposed that the observed small grains are assigned to anatase and the large grains are assigned to rutile. Nucleation and crystal growth of $\mathrm{TiO}_{2}$ possibly proceeds at the vicinity of the fiber surface during pyrolysis. It is, however, remained issue that the obtained fiber is far weak as compared with the fiber derived from the $\mathrm{SiCl}_{4}$ cured fiber. The $\mathrm{TiO}_{2}$ grains on the fiber acts as surface defects, and the strength is apparently low. Ishikawa et al. reported the successful production of flexible $\mathrm{SiO}_{2}-\mathrm{TiO}_{2}$ fibers by using polycarbosilane (PCS) base precursor [8,9]. To be used as fabrics, like such previous $\mathrm{SiO}_{2}-\mathrm{TiO}_{2}$ fibers derived from polycarbosilane, the amount of $\mathrm{TiCl}_{4}$ captured in the silicone resin fiber must be controlled at a low content to reduce the resin fiber swelling during the curing and the $\mathrm{TiO}_{2}$ crystal growth at the fiber surface during the pyrolysis.

\section{Summary}

The Si-O-C fiber derived from the silicone resin fiber cured by the $\mathrm{SiCl}_{4}$ shows oxidation resistance at 1511 and $1606 \mathrm{~K}$ in an air flow. The surface of the fiber shows cracks. The fiber, however, holds straight shape even after partial fusing. The conversion of the Si-O-C to silica is suggested to be limited at the fiber surface. During the $\mathrm{TiCl}_{4}$ vapor curing, the resin fiber captured a large amount of $\mathrm{TiCl}_{4}$, and the residual mass gain after hydrolysis becomes 40 mass\%. After the pyrolysis in an air flow, the amorphous $\mathrm{TiO}_{2}$ in the fiber is mainly converted to anatase, while that in the cured fiber is mainly converted to rutile after the pyrolysis in an Ar flow. The nano grains observed on the fiber surface are assigned to anatase, while the relatively large micro grains observed on the fiber are assigned to rutile.

\section{Acknowledgements}

This work is partly supported by a Grant-in Aid for Scientific Research C (No. 20560627) from Japan Society of Promotion Science. We thank to Professor Young-Wook Kim (The University of Seoul) for information about physical - mechanical properties and applications of YR3370 resin.

\section{References}

[1] G. T. Burns, R. B. Taylor, Y. Xu, A. Zangvil and G. A. Zank: Chem. Mater. Vol. 4 (1992), p. 1313.

[2] T. Rouxel, G. D. Soraru and J. Vicens: J. Am. Ceram. Soc. Vol. 84 (2001), p. 1052.

[3] G. D. Soraru, L. Pederiva, M. Latournerie and R. Raj: J. Am. Ceram. Soc. Vol. 85 (2002), p. 2181.

[4] M. Narisawa, R. Sumimoto, K. Kita, H. Kado, H. Mabuchi and Y. W. Kim: J. Appl. Polym. Sci. Vol. 114 (2009), p.2600.

[5] P. Baldus, M. Jansen and D. Sporn: Science Vol. 285 (1999), p. 699.

[6] T. Suminoe, K. Matsumura, N. Tomomitsu, in Japan Patent 88099 (1978).

[7] M. Narisawa, R. Sumimoto, K. Kita, Y. Satoh and H. Mabuchi: Ceramic Transactions, accepted.

[8] T.Ishikawa T, H. Yamaoka, Y. Harada, T. Fujii, T. Nagasawa: Nature, Vol. 416 (2002), p. 64.

[9] T. Ishikawa: Int. J. Appl. Ceram. Technol., Vol. 1 (2004), p. 49. 